\title{
Gênero, sexualidade e educação física: formação e prática docente
}

\author{
Gender, sexuality and physical education: teacher training and practice \\ Género, sexualidad y educación física: formación y práctica docente
}

\author{
Milena de Bem Zavanella Freitas ${ }^{1}$; OSMar MOREIRA De SOUZa Junior ${ }^{2}$ \\ UNIVERSIDAde FEDERAL DE SÃo CARLOS, UFSCAR, SÃo CARLOS-SP, BRASIL
}

\begin{abstract}
RESUMO
A Educação Física escolar é um meio cujas diferenças de gênero emergem de modo hierárquico, da mesma forma que a sexualidade se torna um problema. A capacidade do(a) docente para intervir sobre atitudes discriminatórias depende de uma formação que contribua para isso. Considerando a graduação um momento importante, esse trabalho tem os seguintes objetivos: analisar como o currículo do curso de Licenciatura em Educação Física de uma universidade pública aborda gênero e sexualidade; analisar de que forma docentes formados(as) por este currículo identificam seu impacto na atuação profissional. Os dados foram obtidos por meio do Projeto Pedagógico, das disciplinas e de entrevistas com docentes formados(as) pelo currículo. Concluímos que a abordagem do curso não é suficiente na preparação de docentes quando o assunto é gênero e sexualidade. Portanto, são apresentadas sugestões para que conhecimentos obtidos na graduação tenham maior proximidade com os desafios da educação formal.
\end{abstract}

Palavras-chave: Gênero. Sexualidade. Formação Profissional. Educação Física Escolar.

\begin{abstract}
Physical Education is a way whose gender differences emerge hierarchically, in the same way that sexuality becomes a problem. The ability of the teacher to intervene on discriminatory attitudes depends on the training that contributes to this. Considering graduation an important moment, this work has the following objectives: to analyze how the curriculum of the Physical Education program at a public university addresses gender and sexuality; analyze how teachers trained by this curriculum identify their impact on professional performance. The data were obtained through the Pedagogical Project, the subjects and interviews with teachers trained by the curriculum. We conclude that the course approach is not sufficient in the preparation of teachers when the subject is gender and sexuality. Therefore, suggestions are made for knowledge obtained in undergraduate courses to be closer to the challenges of formal education.
\end{abstract}

Keywords: Gender. Sexuality. Professional Qualification. School Physical Education.

\section{RESUMEN}

La educación física escolar es un medio en el cual las diferencias de género surgen jerárquicamente, de la misma manera que la sexualidad se convierte en un problema. La capacidad del maestro para intervenir en actitudes discriminatorias depende de la capacitación que contribuya a eso. Considerando la graduación como un momento importante, este trabajo tiene los siguientes objetivos: analizar cómo el plan de estudios del curso de Educación Física en una universidad pública aborda el género y la sexualidad; Analizar cómo los maestros capacitados por este plan de estudios identifican su impacto en el desempeño profesional. Los datos se obtuvieron a través del Proyecto Pedagógico, las asignaturas y entrevistas con docentes formados por el currículum. Concluimos que el enfoque del curso no es suficiente en la preparación de los maestros cuando la temática es género y sexualidad. Por lo tanto, se hacen sugerencias para que el conocimiento obtenido en los cursos de pregrado se acerque más a los desafíos de la educación formal.

Palabras clave: Género. Sexualidad. Formación Profesional. Educación Física Escolar.

\footnotetext{
1 Mestranda em Educação pelo Programa de Pós-Graduação em Educação da UFSCar. E-mail: debem.milena@gmail.com. ORCID: http://orcid.org/0000-0001-8999-6753.

${ }^{2}$ Professor Adjunto no Departamento de Educação Física e Motricidade Humana (DEFMH) da UFSCar, coordenador e professor do Mestrado Profissional em Educação Física em Rede Nacional (PROEF), polo UFSCar. E-mail: osmar.ufscar@gmail.com. ORCID: http://orcid.org/0000-0002-2915-5634.
} 


\section{INTRODUÇÃO}

As identidades pessoais são associadas a marcadores sociais como, por exemplo, classe, raça/etnia, gênero, crença religiosa e são aspectos que constituem os sujeitos. Stuart Hall (2002) amplia a compreensão da categoria identidade, ao sugerir que toda identidade é móvel e pode ser redirecionada. De acordo com o autor a utilização do termo identificação ou da expressão processo identitário confere um significado mais adequado às representações expressas nas culturas, nos sujeitos e nos espaços.

Hall (2002) sustenta que as identidades não são fixas ou imóveis, não admitindo, portanto, sua compreensão como entidades dotadas de um caráter de verdades absolutas. O ser humano é concebido por meio de processos identitários diversos e mutáveis, nos quais não existe uma maneira única e correta de viver e experienciar o mundo. Portanto, o gênero e a sexualidade são integrantes das identidades dos sujeitos, são aspectos que concebem práticas sociais e instituições, assim como também são criados e reproduzidos por essas instâncias (LOURO, 2003).

Scott (1995) apresenta gênero como uma categoria de caráter social utilizada para se contrapor ao determinismo biológico vinculado às diferenças percebidas entre os sexos. O conceito é utilizado como ferramenta política e pedagógica para discutir desigualdades e relações de poder existentes entre homens e mulheres. As diferenças entre os sexos nas esferas social e cultural emergem com base em representações simbólicas que encontram seus lugares em feminilidades e masculinidades que, por sua vez, são construções que se transformam ao longo da história em cada civilização (LOURO, 2011).

A sexualidade é um conceito que frequentemente associa-se ao gênero. Em um discurso normativo automaticamente também é vinculada ao sexo biológico, entretanto trata-se de outro marcador social que possui o fator social como determinante, dessa forma possui igualmente a capacidade de transformar-se enquanto maneira de se relacionar sexualmente (LOURO, 2011).

Considerada assunto pertinente a ser tratado ao nível do indivíduo, do privado, aparentando não conter dimensões culturais, a sexualidade dificilmente é debatida na esfera social o que favorece alienar-se de que ela também se constrói por meio dessa dimensão (LOURO, 2000). De imediato é preciso criar espaços para a problematização dessas questões a fim de garantir o direito à experimentação e à manifestação do ser que se é, de modo que as relações superem a normatização e acolha a diversidade.

Meyer (2010) aponta que no campo da educação, ponto de partida sobre o qual se opera, há um padrão que de tão difundido ao meio é considerado natural aos olhos da sociedade. Há uma norma que parte da masculinidade branca, heterossexual, de classe média e judaico-cristã. Em um viés comparativo há também o que é diferente, ao que chamamos de minorias, porém não são minorias em quantidade, mas por estarem em condições sociais inferiores. Ao compreender essa organização é importante reafirmar que as normas e as diferenças são produzidas socialmente e que nós, indivíduos que convivemos em sociedade, somos responsáveis por essa organização sofrendo com as imposições ou as reforçando.

Em programas educacionais a inclusão é uma perspectiva frequentemente adotada com a intenção de garantir a equidade de direitos entre os indivíduos, propondo uma atenção diferenciada àquelas(es) que por distintas razões sofrem algum tipo de discriminação. Dessa forma, existem especificidades referentes a cada grupo de pessoas e suas necessidades que, no escopo da produção de conhecimento e da prática educacional, nos convida a direcionar o olhar para recortes específicos da inclusão, como gênero e sexualidade (GOELLNER, 2009). 
Considerando que a graduação é um momento importante para a formação de professoras(es), esse estudo buscou analisar se o currículo vigente do curso de Licenciatura em Educação Física de uma universidade pública paulista apresenta indicativos sobre abordagens acerca de gênero e sexualidade, assim como analisar de que forma professoras(es) graduadas(os) por este currículo identificam o impacto da formação na atuação profissional frente a situações que centralizem o tema gênero e sexualidade.

\section{Processo metodológico}

Foi realizada uma pesquisa qualitativa de caráter exploratório. O primeiro conjunto de informações foi obtido por meio da análise de documentos que compõem o currículo do curso de Licenciatura em Educação Física da universidade pública pesquisada. Primeiramente foi analisado o Projeto Pedagógico que junto com a matriz curricular de disciplinas embasa toda a estrutura curricular do curso. A intenção é levantar informações que possam indicar se existe e como se dá a abordagem sobre os temas sexualidade e gênero.

O outro conjunto de dados foi recolhido por meio de entrevistas semiestruturadas (NEGRINE, 2013) realizadas com professoras(es) formadas(os) por esse currículo, com a intenção de coletar informações a respeito do que foi trabalhado com as(os) professoras(es) ao longo da trajetória da graduação.

Consideramos que as entrevistas permitem, minimamente, verificar como foi conduzida a abordagem da temática durante a graduação e se houve suporte para que as(os) profissionais pudessem lidar com o tema. Também foram observados outros fatores importantes como: qual a disposição e interesse das(os) educadoras(es) em incorporar a temática em seus planejamentos e aulas ministradas; qual nível de segurança sentem para desenvolver diálogos e atividades que se relacionem com o tema; como essas questões estão presentes no cotidiano escolar, entre outras.

A seleção das(os) participantes da pesquisa se originou de uma lista com os nomes e e-mails das pessoas formadas pelo currículo ${ }^{3}$ de licenciatura, solicitada na secretaria do curso de Educação Física. Foi obtida uma lista contendo o nome de 188 pessoas graduadas e 178 endereços de e-mails fornecidos pela secretária do curso. Após as tentativas de contatar essas pessoas por e-mail e pela rede social Facebook, foram recebidas 66 respostas sendo que 39 das pessoas que responderam afirmaram que nunca haviam trabalhado em escola após a formação; 11 pessoas já haviam atuado, mas abandonaram por falta de adaptação, interesse ou oportunidade e, por fim, 16 pessoas responderam afirmando que trabalhavam com Educação Física escolar naquele momento.

Das 16 pessoas que responderam que atuavam na Educação Física escolar foram feitas entrevistas com oito delas por meio de encontro presencial ou via rede social Skype. Quanto às demais pessoas, duas tiveram problemas com o meio eletrônico de comunicação, quatro estavam indisponíveis no período necessário para realização da entrevista e duas pararam de responder as mensagens enviadas.

Para a realização das entrevistas foram criadas três questões abrangentes apresentadas de uma vez, denominadas disparadoras, a fim de estimular a(o) entrevistada(o) a falar mais livremente e apresentar reflexões pessoais sobre o tema. Após as respostas obtidas sobre essas primeiras questões, outras cinco mais diretivas

\footnotetext{
${ }^{3}$ A coleta de dados utilizou o currículo vigente no ano de 2016, data em que foi feita a pesquisa original. Este currículo é utilizado como referência para o curso de licenciatura desde o ano de 2005.
} 
foram feitas a fim de garantir que as falas contemplassem reflexões específicas sobre o tema.

Os resultados obtidos foram organizados em quatro tópicos: o currículo do curso de licenciatura em educação física da universidade; limites e possibilidades na atuação docente; gênero e sexualidade na formação e seus impactos na intervenção docente; sugestões para a abordagem da temática gênero e sexualidade no processo de formação.

\section{O CURRÍCULO DO CURSO DE LICENCIATURA EM EDUCAÇÃO FÍSICA DA UNIVERSIDADE}

Nessa seção será apresentada uma breve análise do Projeto Pedagógico do Curso de Licenciatura em Educação Física da universidade (PPCLEF) ${ }^{4}$ e das disciplinas obrigatórias oferecidas pelo departamento do curso para explorar aspectos gerais e específicos que se relacionam com o propósito do trabalho.

Embora o PPCLEF contemple a temática diversidade social e cultural, as orientações são tímidas e de forma geral não existe uma elaboração sobre o que se espera quando se fala de diversidade. O PPCLEF traz como preocupações atuais a necessidade de se ter uma formação com ênfase tanto no ensino quanto na pesquisa cuja prática pedagógica esteja constantemente vinculada à construção de conhecimentos. Também considera o papel do(a) professor(a) como agente social que contribui para a formação da cidadania de escolares, possibilitando a construção de um pensamento coletivo para a superação de desigualdades sociais.

Foi possível identificar preocupações quanto à formação que aborde questões socioculturais, promovendo atitudes baseadas no respeito e acolhimento das diversas manifestações de identidades, por meio de uma ação pedagógica justa e acessível a todas(os). Porém é preciso considerar que é necessário tratar essas questões com mais atenção, pois são diversas as problemáticas sociais que afligem as pessoas não só no âmbito escolar, mas também na vida, como o racismo, sexismo, machismo, homofobia, classicismo, entre outras formas de discriminação que muitas vezes culminam em atos de violência explícita.

Quanto às disciplinas ofertadas pelo departamento do curso, existem 24 que são obrigatórias para graduandas(os) em licenciatura. Os planos de ensino das disciplinas estão inseridos no website que maneja trâmites burocráticos de todos os cursos do campus da universidade. Os elementos presentes nos planos de ensino são basicamente: equipe, objetivos, carga horária, ementa, tópicos, recursos e referências bibliográficas.

Entre as 24 disciplinas de caráter obrigatório ofertadas pelo departamento do curso encontra-se o termo gênero em quatro delas e sexualidade em uma disciplina. Entre as quatro que apresentam gênero, em uma delas o termo aparece na ementa, mas entre os tópicos, que são os objetivos e os conteúdos organizados em unidades didáticas, o termo não é mais mencionado. Em duas disciplinas o gênero aparece como ponto central de um tópico e em uma disciplina a reflexão sobre questões de gênero aparece como objetivo específico e tem um tópico destinado ao tema. O termo sexualidade está presente em apenas um plano de ensino entre todas as 24 disciplinas. $\mathrm{O}$ termo encontrase em um tópico que tem como objetivo caracterizar aspectos gerais de deficiências intelectuais.

Por meio das orientações adotadas pelo curso de Licenciatura em Educação Física, compreendemos que existe uma preocupação com a formação de professoras(es)

\footnotetext{
${ }^{4}$ Cabe ressaltar que o documento não será referenciado no texto para preservar o sigilo em relação à instituição de ensino superior pesquisada, mas o documento é público e está disponível no website da instituição.
} 
que tenham uma ação pedagógica para além da transmissão de conhecimentos, que sejam capazes de articular a atuação docente com a gestão dos acontecimentos nos meios dessa atuação, somados ao exercício da pesquisa que permite a reflexão sobre a prática.

Mesmo havendo preocupações apontadas no PPCLEF sobre questões socioculturais, não há especificações de como deverá ser feito o tratamento frente a questões de gênero e sexualidade. Consequentemente, também não é apresentada uma abordagem pedagógica e política específica para o assunto, assim como para outros temas, deixando inconsistente e indefinida a relação que o curso irá estabelecer com a temática ao longo da graduação. Da mesma forma, ao analisar os planos de ensino das disciplinas, não há uma consistência sobre a abordagem do tema de tal maneira que seja possível reconhecer uma intenção de aprofundar a discussão em um viés interdisciplinar, como acontece com vários outros temas.

É preciso ressaltar que a falta de referências concretas de políticas e ações pedagógicas direcionadas para as questões de gênero e sexualidade contribui para o processo de produção das normatizações e das desigualdades, o que pode chegar a se reproduzir tanto na formação acadêmica como na atuação docente no espaço escolar.

\section{LIMITES E POSSIBILIDADES NA ATUAÇÃO DOCENTE}

Nos dias atuais é comum encontrar educadoras(es) que vivenciam situações marcadas por provisoriedade, precariedade e incerteza no trabalho realizado. Do mesmo jeito que é muito difícil negar as sensações de vulnerabilidade e despreparo experimentadas por essas(es) profissionais ao se depararem com as circunstâncias de imprevisibilidade do cotidiano escolar (LOURO 2010).

A maior parte dos relatos das(os) entrevistadas(os) indica que nem sempre há um currículo que as(os) professoras(es) possam se basear para planejar as aulas e quando ele existe é qualificado como falho ou insuficiente a respeito de gênero e sexualidade.

Não sei se você conhece a apostila do Estado [...] É bem bobo assim, acho
por algumas coisas, umas coisas são legais e outras são bem bobas. Tipo ah,
para terceiro colegial, uma pergunta: boxe é pra menino ou menina? Lavar a
louça... É uma coisa legal, já introduz, mas é muito pouco. [...] Muito pouco
se for pensar numa pessoa que não teve contato, não teve acesso a essa parte
na graduação, fica difícil você tentar trabalhar só o que veio pelo Estado
(Mayara $^{5}$, professora do Ensino Fundamental - anos finais e do Ensino
Médio).

A professora Mayara é a única entre todas(os) entrevistadas(os) que atua em escola estadual. Nesse trecho comenta sobre a qualidade do material oferecido pela rede estadual de ensino e destaca a superficialidade do suporte oferecido pelo material, principalmente para professoras(es) que não tiveram acesso a esse tipo de conteúdo na graduação. Com essa fala pontua-se uma breve análise sobre o currículo do Estado a respeito de gênero e sexualidade.

Uma simples consulta ao currículo do Estado de São Paulo, disponível na plataforma online da Secretaria de Educação, permite perceber que os tópicos que introduzem os fundamentos para o ensino da Educação Física, tanto nos anos finais do Ensino Fundamental quanto no Ensino Médio e as recomendações feitas para a abordagem dos conteúdos, abordam com prevalência as dimensões conceituais e

\footnotetext{
${ }^{5}$ Os nomes dos(as) professores(as) entrevistados(as) são todos fictícios, visando preservar a identidade dos(as) colaboradores(as) da pesquisa.
} 
procedimentais das práticas corporais ${ }^{6}$. Apenas para o Ensino Médio verifica-se a presença de conteúdos transversais a serem trabalhados na dimensão atitudinal. Considerando essas informações percebemos que somente o gênero possui espaço, ainda que de maneira superficial e sem suporte bem definido para que promova discussões aprofundadas sobre o tema (SÃO PAULO, 2012).

Além disso, alguns(as) entrevistados(as) indicam que a dinâmica do cotidiano escolar de professoras(es) de Educação Física é outro fator. Entre as dificuldades estão: tempo e número de aulas destinadas à Educação Física; quantidade de estudantes por turma; evasão de estudantes; variação das idades dos(as) escolares, entre outras.

\begin{abstract}
Eu tento conversar com eles, eu acho que acaba acontecendo que não sai da mesma coisa e é muito difícil você parar. Por exemplo, acontecem alguns problemas, você tem quarenta alunos numa sala, você tá com problema com dois, aí tem outros dois que estão fazendo outra coisa, enquanto os outros estão fazendo outra coisa. É uma aula de cinquenta, é de cinquenta ou uma hora e quarenta que você tem que chegar, fazer chamada, até arrumar todo mundo, então não dá tempo de fazer muita coisa, muitas vezes não dá tempo de parar, de conversar com eles. Aí bate o sinal já tem que levar eles para a sala se não eu tenho problema com outro professor ou com a diretoria. Aí vai ficar para outra semana, e aí duas aulas por semana é muito pouco, uma coisa que aconteceu na outra semana e que geralmente eles nem lembram mais e que eles nem querem discutir, eles não querem falar sobre [...] Aí é uma coisa que eu acho que falta ainda, tentar pegar, falar sobre com os alunos, tentar resolver esses problemas. Muitas vezes eu finjo que não aconteceu porque eu tenho muitas outras coisas para fazer durante a aula, com muitos alunos e não dá pra parar com dois, três ali. [...] E como é que você pega, ah semana que vem eu vou tentar resolver, mas na semana aconteceu tanta coisa em tantas outras escolas, que você acaba deixando passar depois (Mayara, professora do Ensino Fundamental - anos finais e do Ensino Médio).
\end{abstract}

A fala de Mayara apresenta inúmeros problemas que refletem na dificuldade da professora para abordar temas como gênero e sexualidade. Ela não minimiza a importância dos temas, pelo contrário, afirma que está em falta, porém a soma de tantos fatores vai na contramão dessa proposta e enfraquece a sua ação.

Entre todos os agravantes que contribuem para dificultar o trabalho das(os) professoras(es) se sobressaem na fala das(os) entrevistadas(os) impedimentos associados à insegurança, imprevisibilidade e falta de conhecimento.

O impacto para mim foi o susto de ver como eu não tinha conhecimento para lidar com aquilo, já tinha ouvido, já tinha visto, principalmente quando tinha recreação que a gente tem essas idades misturadas. Mas, eu senti uma deficiência muito grande, para mim foi assustador ver como eu não sabia (Maria Fernanda, professora do Ensino Infantil e do Projeto Mais Educação).

As dificuldades encontradas durante o ensino podem, por vezes, levar o(a) professor(a) a desistir e abrir mão de intervir em situações nas quais um posicionamento crítico é necessário. Evitar os conflitos ou não saber lidar com eles possibilita abrir um caminho para a intolerância, discriminação e violência, por isso estar preparada(o) para mediar conflitos existentes se torna um desafio para educadoras(es), assim como superar as próprias limitações e inseguranças (ALTMANN; AYOUB; AMARAL, 2011).

\footnotetext{
${ }^{6}$ A dimensão conceitual refere-se aos saberes ligados aos fatos, princípios e conceitos (saber sobre, conhecer); a procedimental aos saberes relacionados às habilidades, destrezas, técnicas, táticas, procedimentos etc. (saber fazer) e a atitudinal aos saberes do campo das normas, valores e atitudes (saber ser e se relacionar) (DARIDO, 2005).
} 
Diante de situações problemáticas, demarcadas pela instabilidade no processo da ação educativa, para muitas(os) "[...] a opção é assumir os riscos e a precariedade, admitir os paradoxos, as dúvidas, as contradições e, sem pretender lhes dar uma solução definitiva, ensaiar, em vez disso, respostas provisórias, múltiplas, localizadas" (LOURO, 2010, p. 42).

[...] então nesses conteúdos que são considerados mais femininos a gente acaba aproveitando para fazer essa discussão, ou então quando tem alguma modalidade ou alguma atividade que é mais... que os meninos sobressaem principalmente por conta da força e as meninas sempre falam: "ah, mas é machismo" (Otávio, professor do Ensino Fundamental - anos finais e Ensino Médio).

Apesar das(os) entrevistadas(os) relatarem que problemáticas sobre gênero e sexualidade são frequentes em diversas situações do cotidiano escolar, poucos planejamentos foram estruturados para que o assunto fosse abordado como tema curricular. Nesses casos, por meio de ações educativas pontuais como, por exemplo, organização e estruturação da rotina, resoluções de conflitos, entre outras, foram criadas brechas para desconstruir normatizações principalmente a respeito de gênero.

Então eu fico o tempo todo, assim, quando eu vejo uma situação dessa, desconstruindo. E você fala assim: "odeio rosa, adoro azul e gente nem por isso sou um menino". Então, é muito assim que eu brinco com eles, sabe? Eu não tive um planejamento para trabalhar específico isso, mas brincadeiras ou comentários assim é que eu procuro desconstruir um pouco eles (Joana, professora do Ensino Infantil e do Ensino Fundamental - anos iniciais).

Quanto às estratégias, frequentemente, aparecem nos relatos apontamentos sobre a organização de aulas de Educação Física em que meninos e meninas fazem aulas mistas. Todas(os) afirmaram que a coeducação é uma estratégia importante para viabilizar situações que favoreçam discussões e desconstruções. Dessa forma, na contramão da tradição que por tempos manteve obrigatória a separação de meninos e meninas nas aulas, a convivência entre ambos(as) se mostrou positiva na superação de estigmas e quebra de paradigmas.

Então assim eu nunca dividia por gênero e sempre fazia com que é... qualquer coisa que fosse estigmatizada que os dois fizessem então, por exemplo, fazer uma menina correr com um menino, mas uma menina que eu sabia que ia ganhar de um menino né, então eu fazia na minha cabeça de propósito para romper isso. Então se eles tivessem isso de que o menino ia ganhar então eu fazia de propósito, de colocar alguém que eu já sabia que era mais habilidosa naquilo para ganhar. Eu falo que eu sou professora de empate, eu sempre vou dar um jeito de empatar (Maria Fernanda, professora do Ensino Infantil e do Projeto Mais Educação).

Altmann, Ayoub e Amaral (2011) entrevistaram professoras(es) de Educação Física que também indicam a coeducação como uma estratégia para minimizar as diferenças entre meninos e meninas. As autoras perceberam que tais experiências possibilitam desconstruções de certos estigmas como, por exemplo, a suposição de que meninas não são habilidosas ou capazes de vivenciar jogos ou esportes, ou ainda que existam atividades específicas para meninos e para meninas. Essa abordagem possibilita compreender que as potencialidades e as limitações não estão associadas aos gêneros e aos sexos, mas que se fazem únicas para cada indivíduo de acordo com sua experiência. 
Além da coeducação, outra estratégia muito utilizada pelas(os) professoras(es) foi o diálogo, tanto para dar início à discussão sobre gênero e/ou sexualidade, como para resolver conflitos que envolvessem essa temática. Foi comum nos relatos de professoras(es) que trabalham com os anos iniciais a intenção de desnaturalizar as normatizações quanto a brinquedos, cores e atividades, por exemplo.

E aí eu dou uma problematizada, pergunto se menino pode brincar de boneca,
aí um ou outro fala: "ah, eu brinco de boneca também". Aí se alguém ri eu
pergunto por que tá rindo, uma coisa assim né. [...] E tinha essa coisa de
menino e coisa de menina com essas crianças aparecia bastante, aí eu
perguntava o que é coisa de menino, por que é coisa de menino e por que não
é de menina, se não pode ser de menina, se a menina não pode brincar disso e
o por quê? E aí geralmente eles não têm muita resposta mesmo e aí eles
percebem isso e aí que pode fazer alguma diferença né? (Leandro, professor
do Ensino Infantil e do Projeto Mais Educação).

O diálogo se mostrou a principal ferramenta utilizada pelas(os) professoras(es) para lidar com conflitos e brigas, porém a maneira como foram conduzidos esses momentos foi diferente para cada educador(a). A estratégia preferencialmente escolhida foi reunir as pessoas envolvidas, conversar separado da turma e se necessário levar depois para todo o restante da classe; para outras(os) o melhor a ser feito foi expor de imediato a situação para toda a turma a fim de que percebam a gravidade do problema; para a maioria dependeu da situação, pois houve a preocupação com a exposição que pudesse gerar desconforto.

Outros recursos e estratégias também foram apresentados: utilização de vídeos, filmes e textos complementares que tratam da temática; promoção de debates nos quais posições diferentes sobre um mesmo tema são defendidas por meio de argumentos consistentes; brincadeiras de descobrir e explorar o corpo; diferentes formas de dividir equipes para os jogos; criação de um quadro de regras de convivência na tentativa de desenvolver a noção de justiça em que todas(os) são responsáveis pela qualidade da convivência.

Sousa e Altmann (1999) explicam que a presença e o posicionamento de professor(as)es são fatores determinantes para o envolvimento das crianças nas atividades escolares. A intervenção docente exerce fundamental influência na problematização de discursos dominantes de gênero e sexualidade, combate à discriminação e à exclusão. Desse modo, o incentivo para que meninos e meninas vivenciem em conjunto as atividades propostas, em equidade, abre caminhos para a desconstrução da normatização de atividades, objetos e modos de se comportar, tidos como masculinos ou femininos.

\section{GÊNERO E SEXUALIDADE NA FORMAÇÃO E SEUS IMPACTOS NA INTERVENÇÃO DOCENTE}

Louro (2003) afirma que as universidades brasileiras em geral possuem poucas disciplinas ou atividades acadêmicas que se propõem a trabalhar com questões de gênero e sexualidade nos cursos de pós-graduação e graduação. Quanto ao curso de Licenciatura em Educação Física da universidade pública pesquisada, um dos questionamentos feitos às(aos) entrevistadas(os) investiga a maneira como foi percebido por elas(es) o tratamento dado a esse assunto durante a graduação e, consequentemente, o impacto sobre a atuação nas escolas. 
As falas que indicam uma influência positiva da relação com o processo de formação e a atuação como educador(a) vão no sentido de estarem mais atentas(os) ao tema. Dessa forma podem agir de forma diferente quando comparado à ausência de um processo de sensibilização. Uma professora entrevistada alegou que o contato com a universidade favoreceu a transformação de sua percepção, passando de uma visão mais conservadora para uma compreensão um pouco mais flexível.

Para ser bem sincera, minha mente só abriu mesmo quando eu entrei na faculdade, que a gente começa a pensar mais nesses assuntos. Então, dando aula eu pude perceber de ser mais amplo, mais aberto com a questão de sexualidade das crianças mesmo. [...]. Se você me perguntasse isso antes da faculdade, eu tenho certeza que não te responderia assim, porque minha mente ainda era muito fechada, mas eu acho que as disciplinas que a gente teve sobre gênero e sexualidade me fez pensar assim, diferente, sabe? (Joana, professora do Ensino Infantil e do Ensino Fundamental - anos iniciais).

Outra professora afirma que a graduação ajudou a ter uma primeira noção do que seria trabalhar com essas problemáticas durante as aulas e que de certa forma amenizou as surpresas que esse encontro poderia proporcionar.

A graduação influenciou muito, porque quando eu entrei, eu não tinha muita noção desse aspecto dentro da sala de aula. Não sabia, tipo, como que funcionava, como que é tratado a sexualidade dentro da sala de aula. [...] Aí a graduação me ajudou pra saber que a gente tem que ter essa noção que a gente tem que trabalhar com isso pra fazer que eles tenham essa noção também (Mayara, professora do Ensino Fundamental - anos finais e Ensino Médio).

Entretanto, outras(os) entrevistadas(os) ao refletirem sobre o processo de formação, as disciplinas e a própria experiência adquirida fora do curso de graduação, consideram que foi insuficiente o tratamento dado sobre gênero e sexualidade no curso de Licenciatura em Educação Física referido.

Eu como professora na minha formação, para faixa etária que eu estou atendendo, não tive suporte. Posso dizer isso com clareza. [...]. Eu não tive isso relacionado a gênero e sexualidade. Para mim, eu dou aquela travada monstra, porque eles perguntaram várias coisas pessoais minhas e eu não sabia como responder para eles (Núbia, professora do Ensino Infantil e do Ensino Fundamental - anos iniciais).

Também foram relatadas algumas lembranças sobre o que foi trabalhado na graduação, como discussões, atividades em disciplinas ou fora da grade curricular obrigatória e destaques do trabalho de docentes:

Acho que inclusive talvez tenha aparecido gênero só nas disciplinas do João
mesmo, quando trabalhava a questão das diferenciações dos esportes, dessa
popularidade, como era encarado cada um dos esportes né, e vôlei para as
meninas e futebol pros meninos e aí tendo preconceito quando tem alguma
diferença nisso. [...] Do Cláudio talvez problematizasse algumas coisas, mas
acho que era bem geral assim [...], então não focava muito nisso não, não era
uma problemática. [...] Eu acho que quando se falava de brincadeiras, não sei
se era a Júlia [...], alguma coisa assim, que se defendia que brincassem todas
juntas, todas as crianças juntas, desde o começo pra se conhecerem,
conhecerem as diferenças entre menino e menina e tal, mas não foi alguma

${ }^{7}$ Os nomes dos(as) professores(as) universitários(as) foram alterados a fim de preservar suas identidades. 
coisa que me marcou [...] Mas eu acho que na questão infantil, por exemplo, da educação infantil, mesmo na disciplina [sobre desenvolvimento motor], acho que fica muito no biológico, genético e coisas assim, eu acho que daria pra ser mais contextualizado (Leandro, professor do Ensino Infantil e do Projeto Mais Educação).

Ao observar a fala do professor Leandro notamos um apontamento importante referente a disciplinas que lidam com o desenvolvimento humano. A abordagem que sobressai foi feita por meio de uma perspectiva biológica, cuja ênfase é sobre capacidades e habilidades físicas. Essa associação, tendo fim nela mesma, sugere a compreensão de que o biológico supostamente seria suficiente para legitimar as diferenças. Esse fato é significativo para um curso de licenciatura, no qual os conhecimentos levados para a escola devem estar articulados com a realidade social, econômica e cultural, por meio de um olhar atento para a multiplicidade de sujeitos e experiências que convivem em comunidade.

$\mathrm{Na}$ fala do entrevistado, ao que se refere às disciplinas obrigatórias, percebe-se que houve um empenho maior de um professor para abordar gênero e sexualidade no curso. Fato que também é apontado a seguir por outro entrevistado ao se referir às disciplinas obrigatórias. Uma delas é do departamento de Educação Física, a outra é oferecida pelo departamento de Educação, cujos(as) professores(as) não são os mesmos para todas as turmas disponíveis, ou seja, é possível que a(o) estudante que cursar com outro(a) professor(a) não tenha contato com o tema.

Foi numa disciplina [...] que na verdade nem é o enfoque da disciplina né? Acho que não deveria ser, mas foi até interessante o professor trazer essas discussões dentro dessa disciplina, mas era bem interessante que ele trazia algumas discussões sobre gênero e sexualidade na escola. E nas disciplinas do João, que ele gostava também de trabalhar com umas situações problemas, então simulação nas aulas de seminário. [...] Eu acho que colaborou sim, de forma ainda que pontual né, em dois momentos nessas disciplinas..., mas a partir de um esforço individual desses professores (Otávio, professor do Ensino Fundamental - anos finais e do Ensino Médio).

Metade das disciplinas do currículo que propõem reflexões sobre gênero, foram ministradas por um único professor e o mesmo é citado pelas(os) entrevistadas(os). Nenhuma outra disciplina analisada e que possui os termos gênero ou sexualidade no plano de ensino é mencionada pelas(os) entrevistadas(os).

Também foram mencionadas intervenções pontuais como, por exemplo, momentos de discussão sobre a temática, atividades práticas, recursos utilizados, ou seja, estratégias variadas que tiveram algum impacto, sendo por vezes incorporadas na atuação pedagógica.

Nas duas disciplinas né, com os dois professores que me lembro de ter trazido essas questões do gênero e sexualidade. Com o da [educação] a gente ficou mais numa discussão teórica né, com o João ele gostava de trazer isso para problematizar durante os seminários e durante a aula. Eu acho que isso eu levei bastante para a aula né, a partir desse exemplo dele de colocar as situações problemas, de problematizar. A gente acaba levando isso depois para nossa prática sim. Então é uma forma de trabalhar, de abordar essa questão nas nossas aulas de Educação Física depois (Otávio, professor do Ensino Fundamental II e do Ensino Médio).

Outro aspecto que merece destaque na fala das(as) professoras(as) refere-se à oportunidade de experimentar a docência no período de formação e assim poder se 
aproximar da realidade escolar e aproveitar melhor o que as disciplinas da graduação tinham a oferecer.

\begin{abstract}
$\mathrm{Na}$ verdade, eu acredito que o currículo da universidade, ele poderia colaborar um pouco mais com a gente nas tomadas de decisão, porque nós como semiprofissionais dentro da faculdade, nós estamos lidando com o público da faculdade e lidar com eles não é a mesma coisa de lidar com crianças. E isso, a única coisa que me trouxe dentro da faculdade foi o PIBID, então dentro do PIBID eu consegui trazer algumas tomadas de decisões, não só em relação a gênero e sexualidade, mas em relação a outras coisas também, que muitas vezes nós não estamos acostumados que não são os nossos assuntos dentro da faculdade (Marcela, professora do Ensino Infantil e do Ensino Fundamental - anos iniciais).
\end{abstract}

Em geral, as(os) entrevistadas(os) relatam que durante o curso de graduação existiram abordagens sobre o tema gênero e sexualidade em momentos pontuais entretanto, ao refletirem sobre a prática pedagógica que exercem nos dias atuais, essas abordagens aparecem como insuficientes, como se estivessem distantes das situações concretas do cotidiano escolar.

Eu acho que é bem deficiente a formação nessa área, eu não sei se é porque depois que a gente sai que a gente vai atuar, a gente percebe o quanto falta para poder trabalhar com isso, mas eu acho que é superficial. É, o que é superficial é isso, como eu tenho que agir numa situação dessa. [...] Então eu tento ir desconstruindo essas relações, mas eu acho que isso na formação da gente, a gente tinha que ter mais específico, entendeu? Que a gente vai no chute né, eu acho que é isso porque para mim isso é certo, mas se é o caminho, não sei né? (Maria Fernanda, professora do Ensino Infantil e do Projeto Mais Educação).

Outro aspecto diz respeito à necessidade de tratamentos específicos de acordo com o ciclo escolar. No relato a seguir a professora percebe o distanciamento entre a teoria e prática quanto ao ciclo de ensino com que trabalha, considerando que a abordagem sobre gênero e sexualidade necessita ter uma atenção diferenciada para cada fase escolar. Assim reivindica uma atenção mais qualificada, a fim de que se tenha uma contribuição que reflita com mais consistência na realidade escolar.

Educação infantil e fundamental I foram duas disciplinas que para mim ficaram muito falhas. [...] E até mesmo discussões relacionadas a esse mundo, porque criança vai brincar, tá, a gente sabe, mas vai aparecer sim muita pergunta: de onde que vai vir um bebê?! Que você vai falar para essa criança, né?! [...]. Então, é uma coisa que para mim ficou bastante falha. Tinham que ter mais discussões, principalmente nessas idades assim menores, porque é uma coisa que você tem que trabalhar desde novinho, né? (Núbia, professora do Ensino Infantil e do Ensino Fundamental - anos iniciais).

Os apontamentos feitos pelos(as) professores(as) entrevistados(as) permitem inferir que mesmo havendo o tratamento sobre gênero e sexualidade no curso de Licenciatura em Educação Física analisado e com algum impacto sobre a prática docente, essa abordagem não se fez suficiente para lidar com a diversidade dos acontecimentos da realidade escolar, fato que contribuiu para inseguranças e até mesmo para o silenciamento em determinadas situações. Nesse sentido, ter um quadro de disciplinas que não dialogam entre si e de certa forma se distanciam da realidade escolar 
contribui para a afirmação de que a graduação poderia aprimorar a abordagem dada às questões de gênero e sexualidade no curso de Educação Física.

\section{SUgestões PARA A ABORDAGEM DA TEMÁtICA GÊNERo E SEXUALIDAdE NO PROCESSO DE FORMAÇÃO}

Louro (2010) afirma que é importante o preparo de educadoras e educadores para compreender como se dá a construção dos discursos normativos, os efeitos desses discursos na vida cotidiana e onde se estabelecem as diferenças. Da mesma forma que tomar consciência de como as instituições lidam com tais diferenças e quais são os valores assumidos possibilita apropriar-se de um posicionamento político crítico no ato de educar.

Sendo assim, quando questionamos como a graduação contribuiu ou poderia contribuir para a preparação de professoras(es), tendo em vista o desenvolvimento de conteúdos que trabalhem gênero e sexualidade, algumas sugestões foram apontadas pela maioria das(os) entrevistadas(os), exceto por uma professora que considerou suficiente o período de graduação.

Entre as sugestões, foi indicada a incorporação do conteúdo em mais disciplinas, além das que já trabalham com o tema.

Na disciplina de planejamento né, e eu acho que quando vai, você pensa no planejamento tem que pensar nas possibilidades e variáveis que tem que acontecer na aula né. E aí acho que pensar em trabalhar com projetos e temas, por exemplo, e como planejar dentro disso (Leandro, professor do Ensino Infantil e do Projeto Mais Educação).

Mais do que associar o tema a um número maior de disciplinas, também foi sugerido que o ideal seria ter uma disciplina exclusiva sobre a temática.

Eu particularmente acho que deveria ter uma disciplina específica né, não sei se agora tem né, mas quando eu fiz não tinha. [...] eu acho que a formação nunca vai dar conta e nem tem como, a gente ia ter que viver na universidade mesmo, mas uma disciplina disso ia ser bem importante eu acho. Nem que fosse optativa né, escolha, mas deveria (Maria Fernanda, professora do Ensino Infantil e do Projeto Mais Educação).

Outra sugestão apontada nas entrevistas foi a possibilidade de ajustar os conteúdos à prática docente auxiliando, por exemplo, nas estratégias adequadas que favoreçam a aproximação entre educadoras(es) e educandas(os).

\footnotetext{
A gente aprende o que é, a gente tem essa noção, mas o que eu tenho dificuldade é como passar isso para os meus alunos, porque eles não têm a mesma carga que eu tinha quando eu entrei, quando eu tive a aula. Então preciso de alguma coisa para eles, para tentar passar para eles de uma forma mais lúdica, mais legal assim que eles tenham interesse, gostem, gostariam de discutir e também que eles consigam entender, uma forma que dê para eles entenderem. Acho que falta um pouco transformar isso em aula, transformar isso em contexto da realidade deles (Mayara, professora do Ensino Fundamental - anos finais e Ensino Médio).
}

Almejando a aproximação da teoria com a prática, outras sugestões foram feitas como, por exemplo, vivências em estágios ou projetos extracurriculares, diálogos com 
pessoas que atuam ou já atuaram no ensino escolar a fim de discutir sobre os problemas reais a serem enfrentados e com isso pensar em estratégias de ensino.

Esse vínculo acho que poderia ser um pouco mais trabalhado ou dentro dos estágios, pensando em alguma coisa, ou mesmo que todos os graduandos tenham a oportunidade de tá dentro duma escola, visitando um PIBID, dando uma aula. Que isso faz muita diferença para a gente, depois quando a gente sai da universidade (Marcela, professora do Ensino Infantil e do Ensino Fundamental - anos iniciais).

Louro (2010) aponta que, para desestabilizar a norma e avançar a discussão sobre o que pertence ao centro e ao que é da margem, é preciso dar um passo adiante para o que vai além do reconhecimento e da aceitação das diferenças e alcançar um estado em que se questione o porquê determinadas características pessoais são percebidas como diferentes ou deturpadas e, assim, acabam por legitimar desigualdades. Devemos nos questionar: qual é o ponto de comparação onde surgem as diferenças? Quais relações sociais estabelecidas a partir dessas diferenças?

Um curso de licenciatura em Educação Física deve providenciar momentos em que a discussão e a problematização de preconceitos se faça presente, que seja real e consistente para que, minimamente, futuros(as) docentes não reforcem estereótipos e atitudes discriminatórias e, mais que isso, avancem para a reflexão e a transformação da realidade em conjunto com a comunidade escolar.

\section{CONSIDERAÇÕES FINAIS}

Considerando que são muitas questões que professores e professoras têm que lidar para conseguir trabalhar gênero e sexualidade em suas aulas como, por exemplo, a presença ou ausência de um currículo que dê suporte, a insegurança para abordar certos temas que geram polêmica e são frequentemente silenciados, entre outras, ficou evidente após as análises das entrevistas que a graduação se configurou um lugar no qual as(os) professoras(es) esperavam encontrar suporte para lidar com problemas correspondentes ao tema.

Quanto ao Projeto Pedagógico é possível concluir que não há indicativos claros para afirmar que a temática é trabalhada no curso e, quando acontece, não é possível compreender sob qual perspectiva e intenção está sendo feita. Em relação às disciplinas, o número daquelas dispostas a trabalhar o tema é baixo e ainda assim nem todas são citadas como significativas pelas(os) entrevistadas(os).

Quanto à prática educativa dos(as) professores(as) formados(as) por este currículo, é possível identificar diversas situações do cotidiano escolar em que gênero e sexualidade estão presentes. Mesmo que não diretamente nos planejamentos, existem ações pontuais que procuram desnaturalizar normatizações relacionadas ao gênero e dar suporte a situações que envolvam questões de sexualidade, principalmente em casos mais delicados.

$\mathrm{Na}$ tentativa de superar as dificuldades, professoras e professores apresentam algumas estratégias. Entre as mais frequentes estão o diálogo e a coeducação, de modo que são utilizadas principalmente com a intenção de combater a discriminação e desconstruir normatizações. Além dessas estratégias são citados outros recursos como a utilização de filmes e aplicação de atividades aprendidas nas disciplinas de graduação.

Deste modo, pode-se concluir que as vivências da graduação geraram algum impacto sobre a prática pedagógica das(os) professoras(es) entrevistadas(os), fato confirmado por ações educativas e exposições dos relatos. Entretanto as(os) 
entrevistadas(os) consideraram que a contribuição dada pelo curso de graduação poderia ter sido mais significativa, de maneira que os conhecimentos adquiridos no curso pudessem se aproximar mais das situações vivenciadas no cotidiano escolar.

Por último, ficam as sugestões para que gênero e sexualidade sejam conceitos mais profundamente trabalhados nos cursos de Licenciatura em Educação Física, com a expectativa de que as insuficiências relatadas possam ser superadas, a partir da aproximação dos conhecimentos acadêmicos com a prática docente do cotidiano escolar, do maior número de disciplinas que dialoguem entre si e com a temática e da criação de uma disciplina para tratar especificamente do tema.

\section{REFERÊNCIAS}

ALTMANN, H.; AYOUB, E.; AMARAL, S. C. F. Gênero na prática docente em Educação física: "meninas não gostam de suar, meninos são habilidosos ao jogar"? Estudos Feministas, Florianópolis, n. 19, v. 2, p. 491-501, 2011.

DARIDO, S. C. Os conteúdos da educação física na escola. In: DARIDO, S. C.; RANGEL, I. C. A. (coord.). Educação Física na escola: implicações para a prática pedagógica. Rio de Janeiro: Guanabara Koogan, 2005. p. 64-79.

GOELLNER, S. V. Corpo, gênero e sexualidade: educando para a diversidade. In: OLIVEIRA, A. A. B.; PERIM, G. L. Fundamentos pedagógicos do programa segundo tempo. Maringá: Eduem, 2009. p. 7388.

HALL, S. A identidade cultural na pós-modernidade. 7. ed. Rio de Janeiro: DP\&A, 2002.

LOURO, G. L. Educação e docência: diversidade, gênero e sexualidade. Formação Docente, Belo Horizonte, v. 3, n. 4, p. 62-70, 2011.

LOURO, G. L. Currículo, gênero e sexualidade: o "normal", o "diferente" e o "excêntrico". In: LOURO, G. L.; FELIPE, J.; GOELLNER, S. V. Corpo, gênero e sexualidade: um debate contemporâneo na educação. Petrópoles: Vozes, 2010. p. 41-52.

LOURO, G. L. Gênero, sexualidade e educação: uma perspectiva pós-estruturalista. Petrópolis: Editora Vozes, 2003.

LOURO, G. L. (org.). O corpo educado: pedagogias da sexualidade. Belo Horizonte: Autêntica, 2000.

MEYER, D. E. Gênero e educação: teoria e política. In: LOURO, G. L.; FELIPE, J.; GOELLNER, S. V. Corpo, gênero e sexualidade: um debate contemporâneo na educação. Petrópoles: Vozes, 2010. p. 9-27.

NEGRINE, A. Instrumentos de coleta de informações na pesquisa qualitativa. In: MOLINA NETO, V.; TRIVIÑOS, A. N. S. (org.). A pesquisa qualitativa na educação física: alternativas metodológicas. Porto Alegre: Editora Universidade/ UFRGS/ Sulina, 1999. p. 61-93.

SÃO PAULO. Currículo do Estado de São Paulo: Linguagens, códigos e suas tecnologias. São Paulo: SEE, 2012. Disponível em: http://www.educacao.sp.gov.br/a2sitebox/arquivos/documentos/782.pdf. Acesso em: 21 jul. 2020.

SCOTT, J. Gênero: uma categoria útil de análise histórica. Educação e Realidade, Porto Alegre, v. 20, n. 2, p. 71-99, 1995.

SOUSA, E. S.; ALTMANN, H. Meninos e meninas: expectativas corporais e implicações na educação física escolar. Cadernos Cedes, Campinas, n. 48, p. 52-68, 1999.

Recebido em: 21 jul. 2020.

Aprovado em: 24 ago. 2020.

Motricidades: Rev. SPQMH, v. 4, n. 3, p. 217-230, set.-dez. 2020 | ISSN 2594-6463 |

DOI: http://dx.doi.org/10.29181/2594-6463.2020.v4.n3.p217-230 